\title{
COOPERAÇÃO ECONÔMICA INTERNACIONAL: ESTUDO DE CASO DA PETROBRÁS: PERSPECTIVAS E ANÁLISE DOS RISCOS ASSUMIDOS NOS INVESTIMENTOS DO BRASIL NA BOLÍVIA.
}

\author{
Elaine Barbosa Santana ${ }^{1}$
}

\section{RESUMO:}

Os elementos conceituais da cooperação econômica são elencados no presente estudo, mostrando a relação política bilateral assignada entre Brasil e Bolívia, especialmente no que tange ao gás bolivianos e a atuação de Petrobrás. 0 conceito de soberania é colocado sob júdice no âmbito do acordo de cooperação firmado com a Bolívia, e a alegação da necessidade de privatização do gás, em virtude de novos parâmetros governamentais sob o Governo de Evo Morales, e as pressões dos movimentos indígenas. As questões jurídicas e econômicas imbricadas na órbita da cooperação e integração são analisadas, mesmo que a opinião pública e a mídia se voltem contra os dispositivos legais.

Nesse contexto, compreende-se que os acordos internacionais sobre as políticas comerciais são processos de cooperação econômica e não de integração como alguns estudiosos apregoam. Pode até ser considerado como uma abertura que favoreça a integração, mas não há supressão de qualquer barreira discriminatória. No caso do Brasil com a Bolívia, ocorreu um processo de cooperação econômica internacional, visto que se trata de acordo que prevê benefícios mútuos e não prevê qualquer uma das fases da integração econômica.

$\mathrm{O}$ recorte do presente manuscrito abrange o direito processual no que se refere aos mecanismos para a concretização da cooperação jurídica no âmbito da organização judiciária, forma de operacionalização, eficácia dos dispositivos que regulam o procedimento e interpretação atribuída a normas relacionadas à temática.

PALAVRAS-CHAVE: Cooperação Internacional; Gás boliviano; Direito Processual; Livre Comércio;

\section{1 - Introdução}

Em sede de considerações iniciais, cumpre destacar que o presente estudo tem por escopo realizar uma leitura, fundamentada nos elementos da cooperação econômica, sobre a relação política estabelecida entre Brasil e Bolívia no caso do Petrobrás.

Com o desiderato de alcançar o sobredito objetivo, cumpre apresentar revisão de literatura sobre a cooperação econômica no âmbito internacional,

\footnotetext{
${ }^{1}$ Elaine Barbosa Santana é mestranda em Direito pela Universidade Católica de Brasília e Coordenadora da Faculdade de Ciências Sociais e Tecnológicas (FACITEC).
} 
buscando elementos que subsidiem a compreensão da temática, bem como referenciar os embasamentos sociais e legais que permearam as tomadas de decisões dos países em tela.

\section{Evolução do instituto da soberania}

Em sede de primeiras considerações, cumpre ressaltar-se que o termo cooperação vem agregando alterações conceituais em decorrência da evolução do instituto da soberania. A mudança do panorama mundial, advindo do processo de globalização, alavanca os alicerces da tradicional noção de soberania. Nesse sentido, entrelaçam-se os conceitos e precisam ser estudados de forma sistêmica em virtude da relação direta nas ações internacionais que afetam a interdependência entre os Estados.

Wight (1985) assevera que as potências que despontam no cenário mundial não são capazes de elaborar toda sua política sem contar com outras potências, apenas utilizando das prerrogativas atribuídas pela soberania. Explica, ainda, ao apresentar a política do poder, que nenhuma potência age em total distanciamento. Nesse sentido, observa-se que o conceito de soberania não poderia ser imutável, vez que a dinâmica de transformação das relações internacionais favorecem as adaptações necessárias.

Com arrimo nas considerações supracitadas, ressalta-se que o conceito de soberania surgiu em um espaço histórico que conduziu o pensamento acerca do assunto para um aspecto restritivo, que, com o passar dos acontecimentos internacionais, incorporaram novos elementos considerando as relações estabelecidas entre Estados e os diversos tratados celebrados. A análise conceitual da soberania deve estar atrelada às condições históricas em que surge o conceito.

Sob a égide do raciocínio acima exposto, registra-se que a análise conceitual do termo soberania vincula-se às condições históricas que são apresentadas. Assim, a clássica concepção da soberania, proposta por Bodin (1956), que não reconhece nenhum superior na ordem interna e não se subordina a qualquer tipo de dependência no plano internacional, não possui respaldo no cenário atual. Segundo Bodin (1956, p. 26 ) "soberania é o poder absoluto e perpétuo de uma República, palavra que se usa tanto em relação aos particulares quanto em relação aos que 
manipulam todos os negócios de estado de uma República". A política internacional demonstrou a imperiosidade de adaptação do conceito à realidade jurídico-social dos Estados conforme aduzido abaixo.

No sentido de observância das altercações advindas no processo de interdependência entre os Estados, surgem diversos entendimentos sobre o instituto da soberania. Alguns doutrinadores, afirmam que a soberania sucumbiu diante da complexidade do processo de globalização, sendo considerada como extinta. Outros divergem quanto ao conceito proposto por Bodin, considerando os aspectos históricos agregados aos elementos vislumbrados pelo referido autor, sem, contudo, deixar de atribuir importância ao instituto da soberania.

Assim, serão apresentados diversos estudos que propõem esclarecer tópicos importantes sobre a temática, bem como a sua relação político-jurídica considerando o processo de globalização. Para tanto, torna-se necessário analisar o conceito de soberania ao longo da história com a finalidade primordial de compreender o seu alcance nos dias de hoje, para, posteriormente, discutir os aspectos relativos à cooperação internacional.

Dallari (2000) afirma que o conceito clássico sobre soberania tem encontrado mais campo de estudo, sendo pesquisado por teóricos do Estado, filósofos do direito, cientistas políticos, internacionalistas, historiadores das doutrinas públicas. Assim, o conceito de soberania, no século XIII com as influências da monarquia torna-se elemento de destaque, mesmo que ainda não definida como elemento do Estado, agregado apenas à afirmação da soberania do monarca.

A partir das concepções acima, no século XVI, Bodin apresenta o conceito de soberania já referido, fornecendo margem de ampliação do conceito e de utilização das características como meio de justificar e adotar políticas internas de proteção. Nesse panorama, Dallari (2000) afirma que atribuir característica de poder absoluto e ilimitado deu margem à distorções ditadas pela conveniência.

Após a constatação das referidas práticas e evolução dos estudos sobre o tema, Rousseau (1996) atribui a titularidade do poder ao povo, suprimindo tal prerrogativa do governante, quando da publicação de "O Contrato Social". Modificase a concepção da soberania, identificando-se três elementos básicos: 1. poder de unificação do povo de um estado; 2. inalienável por ser o exercício de vontade geral; e, 3. indivisível porque a vontade só é geral se houver a participação do todo. 
Afasta-se a soberania do Estado e nele concentra sua legitimidade, afastando a idéia de soberania como forma de poder do governante.

Atualmente, o conceito de soberania está mitigado e não se restringe apenas a aspectos conceituais e de competência. Tornou-se premente a positivação jurídica do instituto, sendo previsto no ordenamento pátrio e em diversos instrumentos internacionais como objeto de observância e de relevância para a concretização das relações entre os Estados, vez que é invocada para justificar práticas dos representantes do Estado, por meio de atos do Poder Público. Seguindo o proposto, é previsto no ordenamento brasileiro, consolidado na Constituição Federal, em seu artigo 1ำ que "A República Federativa do Brasil, formada pela união indissolúvel dos Estados e Municípios e do Distrito Federal, constitui-se em Estado Democrático de Direito e tem como fundamentos: I - a soberania; II - (...)" legitimando assim, não só o seu uso pelo Estado brasileiro, como por qualquer operador do Poder Público.

Apesar de positivado juridicamente, persiste a dificuldade de identificar de forma definitiva o instituto da soberania, em decorrência da diminuição das fronteiras, fenômeno observado em decorrência da globalização política, social, cultural e econômica. Nesse diapasão, em termos de política econômica, Lobo (2001, p. 5) ensina que:

\begin{abstract}
a globalização econômica procura transformar o globo terrestre em um imenso e único mercado, sem contemplação de fronteiras e diferenças nacionais e locais. Tende a uma padronização e uniformização de condutas, procedimentos e relevâncias relativamente aos objetivos de maximização econômica e de lucros, a partir dos interesses das nações centrais e empresas transnacionais que, efetivamente, controlam o poder econômico mundial, sem precedentes na história.
\end{abstract}

Atualmente, em virtude da formação dos blocos regionais, apresenta-se de forma mais veemente a referida mitigação do instituto da soberania, vez que a necessidade, advinda do anseio de alcançar determinados objetivos comuns, determinam mudanças internas e externas que limitam o alcance dos poderes dos Estados em determinadas esferas. Nesse sentido, cumpre destacar o Acórdão número 06/64 do Tribunal de Justiça das Comunidades Européias que corrobora as assertivas acima expostas conforme aduzido abaixo:

(...) ao criar uma comunidade de duração ilimitada dotada de instituições próprias, de personalidade, de capacidade jurídica, de capacidade de representação no plano internacional e, mais precisamente, de efetivos poderes oriundos de uma limitação de soberanias ou de uma transferência de poderes dos Estados para as Comunidades, estes limitaram seus 
poderes soberanos e, assim, criaram um corpo de leis aplicável tanto aos seus respectivos cidadãos como a eles próprios (...).

Assim, o conceito de soberania também passa por adaptações para que não se afaste da realidade. Nesse sentido, Miranda (2004) afirma que a acepção da palavra soberania foi amplamente estudada no âmbito da teoria política e na Filosofia do Direito ocidental. Segundo o autor, apesar de ter sido concebido como um dos pilares da moderna concepção de Estado-Nação, o conceito vem sendo modificado no decorrer do percurso histórico entre o século XVI e o presente. Contudo, não se concebe a exclusão da Soberania do Estado por ser primordial para manutenção da autonomia e poder de decisões:

Falar do fim da soberania como atributo do Estado Nacional parece-nos, portanto, na linha de Habermas, algo precipitado. Sem dúvida, com as transformações na ordem econômica, sociopolítica e tecnológica mundial, além dos acontecimentos históricos recentes, é evidente o processo de relativização da soberania, sem que se perceba, no entanto, no horizonte histórico imediato, o seu desaparecimento (MIRANDA, 2004, p. 87).

Sobre a temática em epígrafe, cabe considerar que o conceito de soberania está imbricado no termo cooperação e integração, em virtude da necessidade de analisar sob outros ângulos os limites atribuídos a cada país e os pontos que devem ser reanalisados para favorecer a ampliação das atividades Estatais na seara internacional e permitir o crescimento diante do contexto globalizado em que está inserido. Nesse sentido, serão discutidos abaixo os principais aspectos relativos à cooperação internacional e, posteriormente, à cooperação econômica internacional para melhor compreensão acerca da temática que se apresenta.

\section{Aspectos relativos à Cooperação Internacional}

Conforme citado no tópico anterior, o instituto da cooperação internacional favoreceu o processo de mitigação do conceito de soberania, visto que para concretização dos princípios que norteiam a referida ação, torna-se imperioso abandonar concepções ultrapassadas para considerar o processo de globalização. Nesse tocante, serão apresentadas discussões acerca dos principais aspectos que permeiam a Cooperação Internacional, considerando conceito, origem, formas e perspectivas internas e internacionais.

Nesse sentido, cabe considerar que 0 instituto da integração e 0 da cooperação não estão definidos de forma clara. Diversos autores relacionam os 
conceitos de forma a não visualizar as diferenças existentes. Segundo Balassa (1980) existem diferenças significativas entre os dois termos tanto no âmbito qualitativo quanto no quantitativo. Assim, apresenta o aspecto da supressão de alguns elementos discriminatórios para a caracterização do processo de integração econômica, visto que a cooperação apenas ameniza a discriminação, não deixando de existir nas relações estabelecidas.

Nesse contexto, compreende-se que os acordos internacionais sobre as políticas comerciais são processos de cooperação econômica e não de integração como alguns estudiosos apregoam. Pode até ser considerado como uma abertura que favoreça a integração, mas não há supressão de qualquer barreira discriminatória. No caso do Brasil com a Bolívia, ocorreu um processo de cooperação econômica internacional, visto que se trata de acordo que prevê benefícios mútuos e não prevê qualquer uma das fases da integração econômica.

Smouts (2004) firma entendimento de que historicamente o discurso sobre a cooperação internacional foi amplamente fundamentado no poder e no direito. Até a Primeira Guerra Mundial valorizou-se essencialmente um direito de coexistência e que foi fulcrada no conceito de soberania e igualdade. Assim, os princípios da isonomia e a prerrogativa da soberania foram elementos que garantiram obrigações para as partes que necessitavam coexistir.

No período da Segunda Guerra Mundial, a concepção realista das relações internacionais foi defendida por vários estudiosos, dentre eles Aron (1986) que criticou as utopias idealistas do século XIX. No seu livro Paz e Guerra entre as Nações ele defende que as utopias concebidas no período entre as duas Guerras não deveriam ser atendidas, visto que foi útil no período da Guerra Fria, o que permitiu o direito de coexistência e de separação pacífica e surgimento da teoria do equilíbrio do poder.

Após o referido período, propagou-se a teoria do "idealismo Wilsoniano" que pretendia abolir a prática da guerra do mundo, consagrando, para tanto, o sistema das Nações Unidas em 1945. Assim, várias abordagens foram utilizadas como mecanismo de proliferação dos idéias de Wilson. Segundo Kissinger (1994), a Liga das Nações manteria a paz por segurança coletiva, no lugar das alianças, sustentando que paz provinha da disseminação da democracia.

Bobbio (2000) assevera que Weber defendia a concepção realista da política que apresentava argumentos contrários aos princípios da concepção idealista, 
apresentando o anseio das nações de possuírem tanto o poder de fato quanto o poder legítimo.

Quando as posturas adotadas por determinados países está alicerçada no "monopólio da força legítima" apresentado por Weber, utiliza-se os mecanismos da força física e geopolítica do Estado. Nesse contexto, Trotski (citado por Bobbio, 2000, p. 133) sugere que "Todo Estado está fundado na força". Acerca destas idéias, Bobbio confirma que

\begin{abstract}
é justo que assim seja. Se houvesse apenas organismos nos quais fosse ignorada a força como meio, o conceito de 'Estado' desapareceria e em seu lugar entraria aquilo que, no sentido particular da palavra, poderia ser chamado de 'anarquia' (BOBBIO, 2000, p. 133).
\end{abstract}

As referidas concepções, apesar de serem propagadas em períodos diversos, fundamentaram diversas práticas e até o presente momento têm forte influência na forma de condução das ações políticas dos países soberanos. No entanto, o processo de globalização, fruto da sociedade moderna e da diminuição das fronteiras culturais, produz benefícios significativos como intercâmbio de conhecimento devido ao avanço da informatização, integração de empresas transnacionais, políticas comerciais de mútua ajuda. Os processos de cooperação econômica deixam de ser apenas de coexistência para alcançar os efeitos da interdependência.

As empresas transnacionais ganham poderes sobre os Estados que precisam estar inseridos no processo de globalização. Tais empresas possuem influência nas injunções políticas e econômicas desenvolvidas pelos Estados, mudanças na ordem social interna de cada país, ingerência nas normas produzidas internamente em virtude de preceitos do direito supranacional. Nesse sentido, Held (2000: 57) afirma que a globalização é facilitada

por tipos diferentes de infra-estrutura - física (como os transportes ou o sistema bancário) normativa (como as regras do comércio), e simbólica (a exemplo do inglês, usado como língua franca) - que criam as precondições para formas regularizadas e relativamente duradouras da interligação global.

Na perspectiva acima, as teorias acerca do uso do poder ganham destaque. Althusser (1997), ao apresentar suas idéias, defende que há um aparelho repressivo do Estado, mas que não se confunde com ele. Freund (2000) explica que Lebrun discorda de Althusser afirmado que o poder não significa necessariamente a posse de meios violentos conforme enfatizado por Althusser. O poder deve permitir influir 
no comportamento de outra pessoa, por exemplo, pela via da força das concepções políticas, pela manipulação de opinião pública, uso do poder para alcançar interesses de minorias.

Apesar das oportunidades advindas do referido processo de globalização, várias alterações na ordem social do país podem ser observadas, implicando profundas mudanças nas relações internas de cada país. Impactos negativos como narcotráfico, crime organizado em escala mundial, dificuldade de solução de controvérsias em decorrências dos paraísos fiscais, principalmente de crimes envolvendo corrupção, envio ilegal de dinheiro para o exterior, lavagem de dinheiro.

Assim, não há como deixar de perceber a importância da ajuda mútua entre os Estados para inibir condutas consideradas anti-sociais, visto que as conseqüências podem ser revertidas em desfavor da própria sociedade. Torna-se premente, ainda, observar as condutas estabelecidas entre os Estados nas relações de reciprocidade estabelecidas, visto a segurança jurídica que deve ser garantida para os membros que participam dos acordos bilaterais, multilaterais ou plurilaterais.

Conforme salientado, em virtude da redução do espaço territorial de cada país que se aproxima pelas relações das sociedades globalizadas, o conceito de Soberania precisa ser repensado de forma a se adaptar à realidade instalada e recepcionar o conceito de cooperação internacional. Nesse contexto, cumpre registrar que as adaptações no ordenamento jurídico de cada Estado e a adequação das políticas estabelecidas são imprescindíveis para que não seja considerado obsoleto e permita que as conseqüências negativas sobrepujem todos os avanços decorridos da interdependência dos Estados.

No tocante à interdependência dos Estados, torna-se premente que ocorra uma coadjuvação recíproca. Verifica-se que vários são os mecanismos que favorecem o auxílio mútuo que ocorrem por meio da celebração de tratados ou de garantia de reciprocidade. Assim, a cooperação internacional vem sendo tema de discussão de diversos órgãos estatais e internacionais.

O Brasil participa de forma ativa na consecução das práticas de cooperação conforme informações constantes no Ministério da Justiça que relaciona diversos acordos firmados com Estados estrangeiros, orientações acerca dos procedimentos adotados. Ademais, participa de redes de cooperação internacional que possuem como finalidade discutir aspectos relacionados à matéria no intuito de encontrar 
estratégias facilitadoras, informativas e promovedoras da cooperação entre os Estados que as integram.

Após a identificação do panorama acima citado, com o intuito de fornecer alguns elementos essenciais para a análise dos pontos relevantes acerca da cooperação jurídica internacional, em decorrência da necessidade de situação da problemática posta.

Com o referido desiderato, observa-se que o termo cooperação foi, na medida em que as relações entre Estados tornaram-se mais valorizadas, evoluindo, buscando se adaptar às necessidades do mundo globalizado. Atualmente existem várias formas de cooperação jurídica que serão apresentadas. Contudo, em decorrência do estudo de caso proposto, será atribuída ênfase na cooperação econômica, para, posteriormente, discutir as questões relativas a investimentos e formas de solução de controvérsias.

Após a apresentação das considerações acima, torna-se imprescindível ressaltar a necessidade de avanço dos estudos relacionados à cooperação internacional para aprimorar o sistema jurídico com a finalidade de inserção e de legislação para permitir a conquista de uma visão global dos efeitos diretos ou indiretos advindos das relações entre os Estados. As referidas práticas propiciarão a elaboração de normas adequadas que permitem o convívio de normas que favoreçam a reciprocidade entre os Estados, que possuirão direitos e deveres inerentes aos países envolvidos.

As referidas observações são afiançadas por Araújo (2003) que ressalta que a posição de um país integrado no sistema internacional depende da credibilidade no contexto internacional e do incremento de suas transações comerciais com parceiros estrangeiros. Para tanto, deve angariar esforços para conseguir produzir críticas que induzam ao aperfeiçoamento de normas internas e no âmbito internacional que favoreçam a prática cooperativa.

Apesar das preocupações no tocante a agressão à Soberania do Estado, é importante frisar que a cooperação internacional não ofende o poder de cada país. Mesmo que exista um tratado ou norma interna no ordenamento jurídico faz-se necessário que os pedidos analisados sejam embasados de forma que a decisão proferida não seja dissonante dos preceitos da ordem pública e o interesse nacional. Ademais, a própria Carta Magna prevê, em seu artigo 4ํinciso XI, que o Brasil rege- 
se nas relações internacionais pelo princípio da cooperação entre os povos para o progresso da humanidade.

Com fulcro na previsão constitucional de princípios que orientam a celebração de tratados que garantam a reciprocidade entre os Estados, o Brasil tem buscado ampliar tais possibilidades. Casella \& Sanchez (2002) apresenta diversos acordos de cooperação judiciária que estabelecem normas de assistência ao estado estrangeiro. Contudo, apesar da existência dos referidos tratados, verifica-se a reatividade quanto à elaboração de procedimentos para orientar a cooperação jurídica internacional.

Para dirimir a problemática acima apresentada, foi designada Comissão para elaboração de um anteprojeto de Lei de Cooperação Jurídica Internacional, cujos artigos propostos prevêem normas reguladoras da Cooperação Judiciária Internacional em diversas matérias. Contudo, o anteprojeto ainda não foi aprovado pelo Congresso Nacional o que dificulta, apesar de ser referencial para algumas decisões, o adequado manejo jurídico da Cooperação entre o Brasil e outros Estados.

Como pode ser observado no anteprojeto, o direito internacional articula-se com matérias de natureza civil, trabalhista, previdenciária, administrativa, comercial, tributária e financeira. Contudo, o recorte do presente manuscrito abrange o direito processual no que se refere aos mecanismos para a concretização da cooperação jurídica no âmbito da organização judiciária, forma de operacionalização, eficácia dos dispositivos que regulam o procedimento e interpretação atribuída a normas relacionadas à temática.

Diante dessa concepção, o tema aponta para um panorama emergido do arranjo de diversos fatores, especialmente a transformação significativa do universo jurídico internacional que vem exigindo, de maneira crescente, a demarcação exata de questões relativas à cooperação internacional. Assim, no momento em que se inicia a abordagem do tema proposto, com a finalidade de versar sobre o problema que permeia o ordenamento jurídico, impõe-se analisá-lo sob a ótica dos aspectos mais marcantes de sua presença.

Ademais, ressalta Valladão (1983) que o Brasil enfrentou de forma veemente a solidariedade internacional, o dever que incumbe aos vários Estados de se auxiliarem reciprocamente. Apesar de tal constatação, não pode ser desconsiderado o fato de a legislação interna e a interpretação consolidada estarem desatualizadas 
e não acompanhar a evolução internacional do mundo globalizado bem como a evolução dos conceitos emergidos de um panorama interno e mundial diverso do atual.

Diante dos meandros que envolvem o tema cooperação econômica internacional, organismos nacionais e internacionais foram criados para regulamentar e auxiliar os Estados nas relações estabelecidas. Diante da importância da Organização Mundial do Comércio, como meio para o desenvolvimento da cooperação econômica, abaixo serão apresentadas algumas reflexões sobre a instituição.

\section{3 . Organização Mundial do comércio e cooperação econômica}

\subsection{Cooperação econômica}

A cooperação internacional econômica, conforme salientado, é uma das atividades diretamente relacionada à ordem econômica internacional que se apresenta no cenário atual. Nessa perspectiva, são abordados aspectos específicos acerca da cooperação no âmbito econômico, considerando as participações do Brasil e a evolução que se observa no quadro de ações relativas à seara em comento.

Para tanto, são utilizados os conceitos apresentados sobre soberania e a evolução do conceito em decorrência da ordem internacional.

\subsection{Livre-comércio e a transformação da economia mundial}

No presente tópico são analisadas as alterações no cenário mundial que interferem nas estratégias desenvolvidas pelas empresas de diversos países que buscam transformações econômicas e tecnológicas mundiais com a finalidade precípua de impor ao livre-mercado produtos ou serviços do país.

Nessa perspectiva, é imperioso ressaltar que os registros do nascedouro do Estado Nacional datam da revolução nacional. Os países como a Inglaterra, França e Estados Unidos da América que foram os primeiros a adotar o modelo em ascensão, caracterizava-se por um mercado razoavelmente seguro, com ganhos de comércio que seriam fruto da divisão do trabalho, visto que o Estado mercantil passa a ser visto como garantidor de proteção do mercado nacional. 
Com as ações concretizadas naquele período, desencadeou-se o processo de revolução industrial que impregnou os Estados com as teorias de cunho liberal. Apesar de Adam Smith (1996), em seu livro Riqueza das Nações, publicado em 1976, apresentar as concepções da teoria econômica liberal, ao contestar o padrão mercantilista de regulação estatal e de controle das riquezas, a prática dos princípios defendidos só foi empregada várias décadas depois. Contudo, ressalta-se que, em decorrência da ampliação das relações internacionais, houve um sobressalto em termos de livre-comércio, possibilitando a utilização de mecanismos adequados para o novo modelo da economia globalizada.

Os estudos acerca dos fenômenos dos mercados não se limitaram ao período de maior evolução. Nesse sentido, cumpre destacar a teoria das vantagens comparativas no comércio internacional apresentadas por Ricardo (1983), segundo a qual a diferença de recursos humanos e naturais de cada país dá a cada um deles uma vantagem comparativa sobre os demais na produção. As idéias de Ricardo foram corroboradas posteriormente pelas teorias da especialização e da economia de escala.

As teorias acima citadas foram essenciais para que fossem vislumbradas as evoluções na prática e nos estudos que subsidiaram o desenvolvimento do comercial internacional. O comércio global e as regulamentações que foram sendo erigidas buscam a regulamentação do comércio de forma internacional. $O$ desiderato sobredito alcançou expressão jurídica no ano de 1944 com a Conferência Econômica e Financeira da Organização das Nações Unidas, celebrada em Bretton Woods, que deliberou sobre a instituição do Fundo Monetário Internacional (FMI), que tinha por objetivos: 1. função promover a cooperação monetária internacional; 2. criação de um Banco Internacional para Reconstrução e Desenvolvimento (BIRD); 3. auxiliar a reconstrução e o desenvolvimento dos Estados mediante o fomento de investimentos de capital com fins produtivos; 4. instaurar medidas adicionais de cooperação econômica internacional, necessárias para facilitar a expansão e o crescimento equilibrado do comércio, com vistas à criação de uma Organização Internacional do Comércio.

\subsection{Brasil e a cooperação econômica}

Considerando os aspectos históricos e as participações do Brasil no campo da cooperação econômica, pode ser ressaltado que estão presentes nos mais diversos grupos que representam os interesses nacionais no âmbito internacional. 
Vários atos econômicos multilaterais foram concretizados desde a conferência de Bretton Woods.

Ao analisar os aspectos contemporâneos, verifica-se que o país possui representantes em diferentes ambientes da diplomacia econômica internacional. Podem ser citadas várias participações desde a conferência acima citada: negociações em curso no Mercosul e países sul-americanos, tentativa de criação de uma Área de Livre Comércio das Américas, Rodada de Doha da OMC e interregionais no Mercosul e União Européia. Nessa perspectiva, cumpre registrar que vários instrumentos de caráter econômico corroboram as ações da diplomacia econômica brasileira, que esteve presente em conferências e reuniões das quais resultaram organizações e instituições multilaterais de caráter econômico.

As decisões e recomendações adotadas pelo Brasil, várias de caráter político, possuem impactos diretos nas relações econômicas internacionais, configurando-se mecanismo extremamente eficaz de construção de alterações na seara econômica nacional. Os instrumentos jurídicos constituem um dos requisitos indispensáveis para a concretização da inserção econômica internacional do Brasil.

Finalmente, registra-se que os elementos apresentados até o presente momento são fundamentais para a compreensão dos reflexos advindos das decisões do governo brasileiro e boliviano sobre os recursos naturais do território boliviano. Assim, os conceitos e evolução do instituto da soberania, a necessidade do estabelecimento de relações internacionais por meio de mecanismos da cooperação internacional, o processo de globalização e de interdependência são essenciais para realização de uma análise perfunctória sobre o caso da nacionalização pela Bolívia dos recursos naturais que, sob força de contrato, estavam sendo explorados pelo Brasil.

\section{O Caso da Bolívia X Brasil}

Em continuidade ao explicitado acima, no presente tópico são realizadas considerações acerca do tratado internacional firmado entre o Brasil e a Bolívia, posteriormente, será apresentado o decreto que a Bolívia publicou nacionalizando os recursos naturais e os argumentos expedidos no documento, para, ao final, articular a literatura mencionada com as decisões adotadas. 
4.1. Tratado internacional que estabeleceu a relação entre o Brasil e a Bolívia

O projeto de construção de gasoduto entre Bolívia e Brasil demorou a ser concebido em função de diversos fatores que emergiram do panorama das negociações e conjeturas históricas, políticas e econômicas dos países envolvidos. No período de negociação a Argentina ainda não era auto-suficiente em gás, pois as reservas naturais não supriam as necessidades de consumo do produto, passando, dessa forma, a exportar o gás da Bolívia.

A partir do momento em que a Argentina não precisou usufruir das reservas naturais da Bolívia, culminando na expiração do contrato em abril de 1992, novas perspectivas surgiram para o Brasil que retomou as negociações com a finalidade de firmar contrato de importação do gás boliviano, visto que a Bolívia dependia, para o crescimento do país, das relações comerciais estabelecidas para exportação do gás.

As tratativas ampliaram-se no final da década de 80 , quando a demanda interna do Brasil exigiu ação brasileira para garantir o consumo interno devido à insuficiência de recursos naturais do próprio país e ao potencial do mercado que se desenvolvia e necessitava de suportes materiais para continuidade das atividades. Nesse sentido, várias ações isoladas foram configuradas na tentativa de buscar soluções para o impasse que se instalava, como por exemplo, a constituição da INFRAGÁS e da Sociedade Privada de Gás- SPG que iniciaram estudos para garantir o crescimento comercial proposto nos projetos em andamento.

Em virtude das diversas pressões advindas da delonga das negociações estabelecidas, o governo brasileiro apresentou análise sobre as necessidades do país, procedendo, para tanto, ao reexame da matriz energética nacional, recomendando a elevação do gás natural para 2010.

Ademais, em virtude da necessidade apresentada de ampliação da aquisição de gás, a Comissão do Gás, criada em julho de 1991 recomendou que a Secretaria Nacional de Energia deveria, entre outras providências:

promover as ações necessárias no sentido de viabilizar, técnica e economicamente, no menor prazo possível, a importação de gás natural da Bolívia, para o atendimento dos mercados dos Estados da Região Sudeste, da Região Sul e do Estado do Mato Grosso do Sul" e, também, que "a Petrobras deveria retomar os estudos para importação de gás da Argentina, via gasoduto, e de outras fontes sob a forma de gás natural liquefeito (GNL), visando a complementação da oferta nacional. 
Após a recomendação realizada, o Presidente da República, em março de 1993, apresentou suas metas de participação do gás natural no consumo de energia primária no Brasil em 2010. Naquela oportunidade, a melhor opção para estabelecer relações internacionais era a Bolívia, em virtude dos contatos anteriormente estabelecidos, considerando os aspectos relativos à política externa do Brasil e a possibilidade de integração futura com os campos produtores de gás da Argentina e o de Camisea no Peru.

Assim, foi instrumentalizada as iniciativas por meio da Carta de Intenções sobre o processo de Integração Energética entre Bolívia e Brasil de novembro de 1991. A referida Carta de Intenções foi assinada entre a Petrobras e Yacimientos Petrolíferos Fiscales Bolivianos (YPFB) com participação do Ministério de Energia e Hidrocarbonetos da Bolívia.

Após a assinatura da referida Carta de Intenções, várias sessões de discussão acerca do projeto foram realizadas na tentativa de garantir os diversos interesses apresentados pelos países. Apenas em fevereiro de 2003 o acordo foi firmado e o contrato de compra e venda entre a Petrobrás e YPFB passou a vigorar. Nas cláusulas contratuais, previa a condição de obtenção de financiamentos que garantissem a viabilidade econômica do acordo estabelecido.

Diante da exigência sobredita, vários percalços ocorreram até a efetivação das exportações. Ocorreram diversas dificuldades de obtenção de investimentos, tornando-se necessários vários aditivos ao contrato inicial, prevendo ampliações de prazos e formas de contraprestação, quantidade de produtos, dentre outros.

Foi por intermédio do Programa Brasil em Ação, proposto em agosto de 1996 que as relações comerciais começaram a se intensificar e viabilizar a consecução do projeto anterior. Contudo, apenas em julho de 1997, foram concretizados os financiamentos e assinados os contratos de construção e montagem do gasoduto.

Os contratos de compra e venda de gás natural da Bolívia compreendiam diversas matérias, pois regulavam a quantidade e ampliação das exportações, capacidade de transporte, a constituição de duas companhias responsáveis pela construção e a operação do gasoduto (Gas Transboliviano S.A. - GTB e Transportadora Brasileira Gasoduto Bolívia-Brasil S/A - TBG, possuindo como sócio a Petrobrás), os investimentos e financiamentos necessários, estrutura do empreendimento compreendendo dimensões, localização, estudos sobre tempo de instalação. 


\subsection{Decreto Supremo n. $028071-10$ maio de 2006}

Por meio do Decreto Supremo n. 28071, o presidente constitucional da República Heróis do Chaco, o Excelentíssimo Senhor Evo Morales Ayma, estabelece que em cumprimento ao estabelecido nos preceitos constitucionais nacionaliza os recurso de hidrocarbonetos da Bolívia. Sob o argumento de que os procedimentos adotados estavam corroborados pelo exercício da soberania nacional e que as medidas decretadas estavam legitimadas pelo mandato do povo boliviano determinou que o Estado recuperasse a propriedade, a posse e o controle total e absoluto dos recursos de hidrocarbonetos.

A referida ação foi fundamentada em diversos argumentos elencados no instrumento sobredito. Dentre eles, relaciona o direito que o povo adquiriu, em decorrência das históricas lutas, de reaver e utilizar em proveito do próprio país os benefícios das riquezas nacionais.

Ademais, em 18 de Julho de 2004 foi realizado referendo vinculante e foi decidido que o Estado Nacional da Bolívia deveria recuperar a propriedade de todos os hidrocarbonetos produzidos no país.

Argumenta, ainda, em sede de considerações introdutórias, que a legislação pátria, em sua carta magna, prevê que os hidrocarbonetos são bens nacionais de domínio originário, direito inalienável e imprescritíveis do Estado, constituindo, dessa forma, propriedade pública inviolável.

Assevera que em decorrência do inciso 5 do Artigo 59 da Constituição Política do Estado, os contratos de exploração de riquezas nacionais devem ser autorizados e aprovados pelo Poder Legislativo. Ademais, com fulcro de justificar as considerações expedidas, apresenta decisão do Tribunal Constitucional $\mathrm{n}$. . 0019/2005 de 7 de Março de 2005. Conflito de leis no tempo e no espaço e recepção dos contratos na Constituição

No instrumento apresenta o argumento de que as atividades de exploração e produção de hidrocarbonetos não cumprem os requisitos previstos na Carta Magna do país e que os contratos firmados estão afrontando os princípios constitucionais considerando que estão atribuindo a estrangeiros a possibilidade de exploração das riquezas nacionais. 


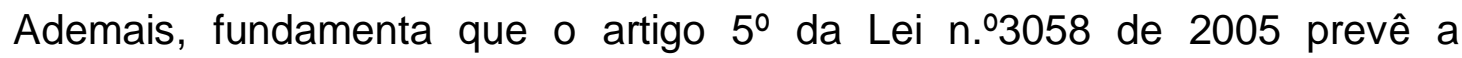
assinatura obrigatória de novos contratos e que o prazo previsto no referido documento legal não teria sido obedecido e que estaria expirado aproximadamente a 180 (cento e oitenta) dias.

Afirma-se que se configurou um ato de traição à Bolívia o processo de capitalização e privatização da Yacimientos Petrolíferos Fiscales Bolivianos (YPFB), visto ser setor estratégico e que está diretamente ligado à soberania e a dignidade nacional.

Cita os artigos 24 e 135 da Constituição Política do Estado, todas as empresas estabelecidas no país são consideradas nacionais e estão submetidas à soberania, leis e autoridades da República e que em decorrência dos referidos artigos e da Lei de Hidrocarbonetos, é vontade e dever do Estado e do Governo Nacional recuperar a propriedade dos hidrocarbonetos.

Destaca, ainda, que o Pacto Internacional dos Direitos Civis e Políticos, o Pacto dos Direitos Econômicos e Culturais, subscritos a 16 de Dezembro de 1966, apregoa que os povos dispõem das riquezas e recursos naturais, sem prejuízo das obrigações que derivam da cooperação econômica, conforme abaixo citado:

Todos os povos podem dispor livremente das suas riqueza e recursos
naturais, sem prejuízo das obrigações que derivam da cooperação
econômica internacional baseada no princípio do benefício recíproco, assim
como no do direito internacional. Em nenhum caso poderá privar-se um
povo dos seus próprios meios de subsistência.

Historicamente, descreve que a Bolívia foi o primeiro país do Continente a nacionalizar seus hidrocarbonetos. Que vários conflitos ocorreram até a conquista das riquezas do país, considerando os movimentos sociais e povos originários que participaram dos movimentos ocorridos no período, com finalidade de recuperar a soberania.

Finalmente, com fulcro nos argumentos expostos, foi decretada a nacionalização dos recursos de hidrocarbonetos do país, dispondo que a partir de 1ำ de Maio de 2006, as empresas petroleiras que realizavam as atividades de produção de gás e petróleo no território nacional estão obrigadas a entregar em propriedade à Yacimientos Petrolíferos Fiscales Bolivianos (YPFB) toda a produção de hidrocarbonetos. Atribui o exercício pleno da propriedade de todos os recursos advindos do território Boliviano e determinando que fique ao seu cargo a operação 
nos campos das companhias que se negarem a acatar ou impeçam o cumprimento do disposto no Decreto Supremo.

Decreta que a atuação das empresas estrangeiras no território Boliviano estava condicionado ao cumprimento das disposições contidas no decreto promulgado, sendo imperioso que, em 180 (cento e oitenta) dias, ocorresse a regularização e atendimento aos dispositivos legais e preceitos constitucionais para o desenvolvimento das atividades de exploração. Nesse sentido, não permitiu que a YPFB executasse qualquer contrato de exploração de hidrocarbonetos, precisando da autorização e aprovação pelo Poder Legislativo.

Em sede de considerações finais, destacam-se algumas observações acerca do período de transição e impõe algumas ações a serem adotadas: 1. O Estado deve possuir o controle e a direção da produção, transporte, refinação, armazenagem, distribuição, comercialização e industrialização dos hidrocarbonetos no país; 2. O Ministério dos Hidrocarbonetos e Energia regulará e estabelecerá as normas referentes às atividades desenvolvidas até que sejam aprovados novos regulamentos de acordo com a Lei; e, 3. O Estado recupera a plena participação em toda a cadeia produtiva do setor de hidrocarbonetos.

\subsection{Análise dos documentos e decisões proferidas}

Após verificação dos elementos que subsidiaram as decisões governamentais brasileiras e os argumentos do decreto supremos, serão propostas algumas lucubrações sobre o assunto, com embasamento teórico da revisão de literatura apresentada.

Streck e Morais (2003) afirmam que uma das instituições que exige maior complexidade de analise é o Estado. Observam-se diversos elementos históricos, econômicos, políticos que influenciam na construção dos ideais nacionais e internacionais, visto que estão diretamente relacionados com a sociedade estão inseridos. $O$ estudo dos referidos autores prevê que

o Estado e suas relações com a sociedade implica, necessariamente, estudar os mais variados aspectos que envolvem o próprio funcionamento das instituições responsáveis por essa sociedade. Estado, Governo, Democracia, Legitimidade, Poder são questões que, imbricadas, exigem uma disciplina para o estudo de suas complexidades (p. 17). 
Nesse momento os elementos da Ciência Política podem subsidiar de forma contundente as interpretações jurídicas adotadas pelos Estados soberanos e fornecer mecanismos essenciais para análise das conjeturas apresentadas.

Assim, as concepções de Bobbio (2003) auxiliam a compreensão do tema quando descreve o Estado, sua origem e evolução, salientando que pode ser entendido como ordenamento político de uma comunidade que surge da dissolução da comunidade primitiva fundada sobre os laços de parentesco e da formação de comunidades mais amplas derivadas da união de vários grupos familiares por razões de sobrevivência interna e externas.

Ocorre que com a concepção do Estado Moderno de um contexto globalizado, o conceito evoluiu, sendo fundamentado em um Estado de Direito, com alicerces constitucionais. Lourival (1953, p. 186) afirma que

\begin{abstract}
a Teoria Geral do Estado converte-se em Teoria do Direito e que não se reduz a significações normativas. A redução do Estado ao direito e a caracterização do direito como complexo de proposições cuja realidade normativa e cujo ser lógico se destaca do que é factual, acarreta a redução do Estado a um objeto ideal.
\end{abstract}

Assim, em decorrência da evolução das concepções do Estado, cabe ressaltar que as concepções de Hobbes (1996) precisam ser aplicadas observando as alterações do mundo moderno. Quando foi engendrada a teoria do Leviatã, em que o Estado era mecanismo criado para evitar que a natureza do ser humano, violenta e impregnada pelo sentimento de que o receio dos semelhantes, impedisse o desenvolvimento da sociedade.

Atualmente, não há mais como defender que sem o Leviatã, metáfora do governo perfeito, estabelecido por meio do contrato social, os interesses dos cidadãos não estariam protegidos, visto que a condição natural da humanidade é de guerra de todo homem contra todo homem.

$\mathrm{Na}$ linha de raciocínio acima, não há como deixar de verificar que os argumentos expedidos no decreto supremo da Bolívia não observaram a evolução do conceito de Estado. Fundamentando-se na teoria de Hobbes quando publica que um dos argumentos do Decreto Supremo é o direito que o povo adquiriu, em decorrência das históricas lutas, de reaver e utilizar em proveito do próprio país os benefícios das riquezas nacionais. Dessa forma, considerou que o Estado é o grande protetor e que os interesses devem estar subordinados em prol do coletivo, para evitar a guerra e propagar a paz interna. 
Pode-se, assim, mencionar Quijano (2004) que assinala diversas questões pendentes na América Latina, ressaltando a necessidade de criação de uma identidade sem máculas do período de colonização, voltando-se para a modernidade, a globalização e a unidade de um povo com princípios próprios. Teme-se pela continuidade e sobrevivência do próprio processo de produção da identidade latino-americana, contudo, o proposto pelo governante da Bolívia traduziu retrocesso no processo de evolução das relações internacionais.

Ademais, como ressalta Wight (1985), os indivíduos não podem viver isoladamente e, ao mesmo tempo, o Estado não pode estar desvinculado do contexto internacional. Dessa forma, a mitigação das concepções trazidas ao tema precisa ser analisada de forma a proporcionar a internalização de conceitos do mundo globalizado, que aspira por novas relações de forma a proporcionar integração e cooperação entre os Estados.

Dessa forma, o argumento expedido de que o decreto foi mecanismo de exercício da soberania nacional não observou qualquer evolução do conceito de soberania. Atualmente, a soberania não pode ser vista como poder absoluto do Estado conforme apregoava Bodin (1956), visto que a interdependência dos Estados não comporta a referida visão. Assim, asseverar que as medidas decretadas estavam legitimadas pelo mandato do povo boliviano e recuperar a propriedade, a posse e o controle total e absoluto dos recursos de hidrocarbonetos pode ser considerada uma medida extremada diante das exigências do mundo globalizado e convivência harmoniosa entre as nações, tanto para proteção dos interesses sociais quanto do próprio Estado soberano.

Nesse sentido, observa-se que, apesar da evolução do direito internacional e da formação de tratados que proporcionam a cooperação entre os Estados soberanos e o desenvolvimento de atividades conjuntas, um referendo realizado em 18 de Julho de 2004 para saber se a opinião da população era a recuperação da propriedade dos hidrocarbonetos produzidos no país foi observado sem sequer revalidar o resultado, visto que o decreto foi publicado aproximadamente dois anos depois, quando o avanço da Teoria do Estado poderia justificar outro resultado.

Foi formalizado acordo entre a Bolívia e o Brasil de cooperação no âmbito econômico de forma a favorecer os interesses de cada Estado, no tocante aos recursos naturais necessários e, em contrapartida, aos investimentos no país cedente. A legislação da Bolívia não sofreu alterações substanciais, nem em sede 
de legislação infra-constitucional e nem na carta magna. Assim, não justificar qualquer interpretação diferente da estabelecida pelo governo anterior.

Conforme explica Miliband (1972, p. 11), "os homens vivem hoje a sobre do Estado" e o governo não pode ser confundido com o Estado, visto que a sociedade ficaria na dependência das origens partidárias do representante. Dessa forma, justificar as decisões descrevendo que a sua Carta Magna prevê que os hidrocarbonetos são bens nacionais de domínio originário, direito inalienável e imprescritível do Estado, constituindo propriedade pública inviolável, gera condição de insegurança jurídica interna e internacional.

Apesar das referidas observações, a decisão do governo da Bolívia foi decretada unilateralmente, fundamentando que o instrumento firmado anteriormente, não cumpre os requisitos previstos na Carta Magna do país e que os contratos firmados afrontam os princípios constitucionais por proibir que estrangeiros explorem as riquezas nacionais. Tais referências, mais uma vez, induzem a sociedade internacional a interpretar que existe uma insegurança absoluta nas relações firmadas com Bolívia, visto que, apesar das lutas da população, os recursos foram explorados historicamente por outros países.

Apesar da proximidade territorial, outros fatores interagiram no processo decisório, principalmente a pressão interna que exigia mudanças estruturais e conjunturais internas e precisava de posturas nacionalistas para garantir uma harmonia nacional. Mesmo o presente argumento é veementemente rechaçado por Wight (1985, p. 155) que defende que os alinhamentos entre os Estados são frutos de pressão internacional e que as pressões internas sucumbem em virtude da necessidade de convivência e interdependência entre os Estados.

Assim, pode-se afirmar que o equilíbrio de poder é um mecanismo à disposição dos Estados para manter um determinado sistema enquanto outros Estados atinjam sua supremacia. Apesar da filosofia de que o equilíbrio deve ser mantido, verificou-se que a supremacia dos interesses internos da Bolívia superou outras iniciativas ou formas de solução da controvérsia, não corroborando premissa de manter e promover a paz, conforme explica Wight (1995, p. 140):

A maioria dos arranjos de poder favorece alguns países, que conseqüentemente procura preservar o status quo, e o justificam como se representasse um verdadeiro equilíbrio. Esses mesmos arranjos são, paralelamente, prejudiciais a outros países, cuja política é revisionista. Assim, a idéia de uma distribuição eqüitativa é retirada expressão 
"equilíbrio de poder", que passa simplesmente a significar a distribuição existente de poder.

Com fundamento nas contribuições apresentadas acima, Kissinger (1994) ao sobrelevar a filosofia apregoada por Wilson, vislumbrava a ordem mundial fundamentada nas atitudes morais, configurando a necessidade de reação apenas quando o fato estivesse em desacordo com os princípios adotados pelo país. Ocorre que não existia fato novo que corroborasse as ações adotadas pela Bolívia. Não houve alteração nos princípios esculpidos no período do tratado. Assim, não se configura ato de traição à Bolívia o processo de capitalização e privatização da Yacimientos Petrolíferos Fiscales Bolivianos (YPFB), pelos benefícios advindos, mesmo considerando que se trata de setor estratégico.

Wilson defendia a concepção de que o poder deve estar atrelado ao alcance da paz. Adotar a postura de que as empresas estabelecidas no país são consideradas nacionais, de que estão submetidas à soberania e de que é vontade e dever do Estado e do Governo Nacional recuperar a propriedade dos hidrocarbonetos, não atende qualquer princípio do direito internacional econômico e poderia ter gerado conflitos de magnitude significativa.

Finalmente, utiliza de forma equivocada, as recomendações do Pacto Internacional dos Direitos Civis e Políticos, o Pacto dos Direitos Econômicos e Culturais. Os referidos instrumentos ressaltam que não poderá, em benefício da cooperação econômica, privar o povo dos seus próprios meios de subsistência. Apregoa que os povos dispõem livremente das riquezas e recursos naturais em conformidade com o tratado firmado pelo Brasil, visto que não se tratou de decisão unilateral e não há prejuízos de subsistência do povo Boliviano em decorrência da celebração.

Nye (2003, p. 33) agrega ao tema argumentos de cunho econômico quando afirma que "o emprego da força põe em perigo as metas econômicas da maioria das grandes potências". Ressalta, ainda, que

\footnotetext{
mesmo os países não democráticos, menos sujeitos à coerção moral popular no que se refere ao uso da força, são obrigados a levar em conta o seu efeito sobre os objetivos econômicos que persegue (p. 33).
}

À guisa de conclusão, não há como deixar de sobrelevar que "os países são disciplinados por uma multidão eletrônica de investidores que controlam o seu acesso ao capital numa economia globalizada" (Nye, 2003, p. 33). Nesse sentido, a 
decisão do Brasil de continuar mantendo relações internacionais com a Bolívia, submentendo-se à condições não exigidas anteriormente precisa ser repensada sob o aspecto da economia política, discussão que merece posterior estudo com análise pormenorizada acerca dos riscos de investimento na Bolívia em decorrência da instabilidade política e insegurança jurídica aos investidores.

\section{REFERÊNCIAS}

ALTHUSSER, L. Aparelhos Ideológicos de Estado, 3ª̣. ed., Rio de Janeiro: Graal, 1997.

ARON, Raymond. Paz e Guerra entre as Nações. Brasília: Universidade de Brasília, 1986.

BALASSA, Bela. Teoria da Integração Econômica. Lisboa: Livraria Clássica Editora, 1980.

BOBBIO, Norberto. Estado, Governo, Sociedade; por uma teoria geral da política, 2003.

BOBBIO, Norberto. Teoria Geral da Política, $8^{\text {a }}$ tiragem, Rio de Janeiro: Editora Campus, 2000.

BODIN, Jean. Los seis libros de la república. Madrid: Tecnos, 2000.

CASELLA, Paulo Borba e SANCHEZ, Rodrigo Elian (orgs.). Cooperação Judiciária Internacional. Rio de Janeiro: Renovar, 2002.

DALLARI, Dalmo de Abreu. Elementos de teoria geral do Estado. 23 ed. São Paulo: Saraiva, 2000.

FREUND, Julien. Sociologia de Max Weber, 5a. ed., Rio de Janeiro: Forense Universitária, 2000.

HELD, David, et al. An Introduction to the globalization debate. Cambridge, England:Polity Press, 2000.

HOBBES, Thomas. Leviatã. São Paulo, Nova Cultural. 1996.

KISSINGER, Henry, Diplomacia das grandes potências. $3^{\underline{a}}$ ed. [...]: UniverCidade, 1994.

LEBRUN, Gérard. O que é Poder?, 14ª . ed., São Paulo: Editora Brasiliense, 1999. MILIBAND, Ralph. O estado na Sociedade Capitalista. Rio de Janeiro: Zaha, 1972.

NADIA, Araújo. Direito Internacional Privado: Teoria e Prática Brasileira. Rio de Janeiro: Renovar, 2003.

NYE JR., Joseph S. O paradoxo do poder americano. Por que a única superpotência do mundo não pode prosseguir isolada (tradução Luiz Antonio Oliveira de Araújo), São Paulo: Editora UNESP, 2002.

QUIJANO, Anibal. O movimento indígena e as questões pendentes na América Latina, Política Externa, No. 4, março, abril e maio, 2004, Brasil, pp. 77-96. 
RICARDO David. Princípios de Economia Política e Tributação' Col. Os Economistas. São Paulo: Abril Cultural, 1983

ROUSSEAU, Jean Jacques. O Contrato Social. Tradução Antonio de Pádua Danesi, $3^{\mathrm{a}}$ edição, São Paulo, Editora Martins Fontes, 1996.

SMITH, Adam. A Riqueza das Nações: investigação sobre sua natureza e suas causas. Coleção Os Economistas. São Paulo: Nova Cultural, 1996.

SMOUTS, Marie-Cloude. As novas relações internacionais - práticas e teorias.

Brasília: universidade de Brasília, 2004.

STRECK, Lenio Luiz e MORAIS, José Luiz Bolzan de Ciência Política e Teoria Geral do Estado, 3" Edição, Livraria do Advogado,2003, p. 17 "Estudar o Estado e suas relações com a sociedade implica,

VALLADÃO, Haroldo. Direito Internacional Privado. Rio de Janeiro: Freitas Bastos, 1983.

VILLANOVA, Lourival. O Problema do Objeto da Teoria Geral do Estado. Recife, Imprensa Oficial, 1953, p. 49 e 175.

VONNEGUT, Kurt. Deadeye Dick. New York: Dell, 1982.

WIGHT, Martin. A política do poder. Trad. Carlos Sérgio Duarte. Brasília:

Universidade de Brasília, 1985.

\section{ACESSO À Internet:}

LÔBO, Paulo Luiz Netto. Direito do Estado Federado ante a Globalização Econômica, Jus Navigandi, Teresina, outubro/2001. Disponível em http://www1.jus.com.br/doutrina/texto.asp?id=2243> .acessado em 15/8/2006. 